Disponível em

http://www.anpad.org.br/rac

RAC, Rio de Janeiro, v. 18, n. 6, art. 5, pp. 832-853, Nov./Dez. 2014

http://dx.doi.org/10.1590/1982-7849rac20141664

$((c))$ EY-No

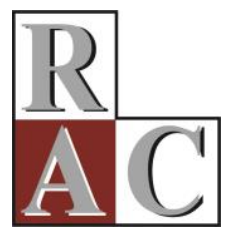

\title{
Recursos e Competências Organizacionais Distribuídos na Saúde Pública
}

\author{
Distributed Resources and Organizational Skills in Public Health
}

Ana Maria dos Santos Carnasciali

E-mail: ana.carnasciali@gmail.com

Fundação Getulio Vargas - FGV

Rua Itapeva, 474, 01332-000, São Paulo, SP, Brasil.

Sergio Bulgacov

E-mail: s.bulgacov@gmail.com

Fundação Getulio Vargas - FGV Rua Itapeva, 474, 01332-000, São Paulo, SP, Brasil.

Artigo recebido em 03.10.2013. Última versão recebida em 03.07.2014. Aprovado em 09.07.2014. 


\title{
Resumo
}

Este trabalho busca contribuir com o entendimento das dificuldades encontradas por organizações com unidades geograficamente distribuídas e que buscam a efetividade no atendimento por meio da distribuição de recursos, em conformidade com as condições geográficas e demográficas, e, neste estudo, especificamente, das populações demandantes dos serviços de saúde. $\mathrm{O}$ estudo de caso escolhido é representativo quanto às decisões sobre as políticas de saúde municipal de distribuição de recursos de pessoal, material e equipamentos e serve como referência às dificuldades inerentes a essas decisões. A base do Sistema de Informações Geográficas (SIG) permite a realização de análises espaciais e demográficas e sua relação com os dados referentes à gestão de recursos e competências ali demandados. A análise com o uso da Visão Baseada em Recursos (VBR) adaptada permite a avaliação das condições internas das decisões no sistema em pauta. Os resultados apontam para os limites da avaliação compartilhada ou isolada da distribuição espacial dos recursos que são comprometidos pelas decisões que envolvem essas duas abordagens. Nesse sentido, a avaliação concomitante dos recursos distribuídos associados ao SIG resulta em importante elemento de análise, pois possibilita a identificação dos recursos estratégicos para um adequado atendimento dos propósitos das Unidades Municipais de Saúde de Curitiba, Paraná.

Palavras-chave: sistemas de informações geográficas; recursos e competências organizacionais distribuídos; área de saúde.

\begin{abstract}
This study seeks to aid understanding of the difficulties that organizations encounter when their units are geographically distributed and they seek to effectively distribute resources in accordance with geographical and demographic conditions. This study specifically looks at those segments of the population that require health services. The case study in question is representative of the decisions regarding municipal healthcare policies concerning the distribution of resources in terms of staff, material and equipment. It serves as a reference for the inherent difficulties of these decisions. The base of Geographic Information System (GIS) enables spatial and demographic analyses and their relationship with the data regarding the management of the required resources and skills. Analysis using an adapted Resource-Based View (RBV) allows evaluation of the internal decisions within the system in question. The results show the limits of the shared or isolated evaluation of the spatial distribution of resources, which are compromised by the decisions involved in these two approaches. In this sense, the concomitant evaluation of the distributed resources linked to the GIS results in an important analysis element, as it enables the identification of strategic resources that adequately satisfy the purposes of Curitiba's Municipal Health Units, in the state of Paraná.
\end{abstract}

Key words: geographic information systems; distributed organizational resources and skills; healthcare. 


\section{Introdução}

Em municípios de médio e grande portes, complexos por sua natureza quantitativa e que possuem unidades de saúde distribuídas geograficamente, são encontradas dificuldades para a adequada distribuição do número e perfil de competências dos profissionais, de medicamentos e equipamentos conforme as necessidades relacionadas aos incidentes críticos que demandam serviços de saúde das populações próximas a essas unidades. É importante destacar que o estudo da relação entre o sistema de informações geográficas com a abordagem de recursos no contexto pesquisado ainda não é encontrado na literatura corrente e seminal da área. Em sentido mais abrangente é possível afirmar que a localização de uma organização e a adequada distribuição de recursos requerem decisões estratégicas que necessitam de estudos criteriosos, e não apenas parâmetros baseados no bom senso e na experiência dos governantes e especialistas. Nesse sentido, Carnasciali e Delazari (2011) demonstram que a Visão Baseada em Recursos (VBR) (Barney, 1996; Wernerfelt, 1984) é a abordagem que contribui para a análise do posicionamento geográfico das organizações distribuídas espacialmente em busca de sua eficiência. Adaptada essa afirmação aos propósitos deste trabalho, a VBR, somada ao Sistema de Informações Geográficas (SIG), permite que os recursos sejam prospectados e analisados para a adequada distribuição dos serviços às populações envolvidas.

Assim, este estudo de caso, realizado em uma Unidade de Saúde, parte de um sistema integrado de atendimento do município de Curitiba, PR, representando grande parte dos fatores que envolvem decisões afetas aos propósitos deste trabalho, ou seja, diversidade geográfica e populacional distribuída, com demandas por serviços diversificados de atenção à saúde; recursos públicos escassos; e programas coletivizados. Importante destacar que o município utiliza parcialmente o sistema, entretanto a pesquisa contribui ao delinear os benefícios da relação gerencial entre o sistema de informações e a análise de recursos na perspectiva inovadora deste trabalho. A pesquisa parte do pressuposto de que a utilização do SIG pode contribuir significativamente para a eficiência do atendimento aos incidentes críticos de saúde ocorridos próximos das unidades e que necessitem de atendimento por meio da disponibilidade de recursos próprios para esse fim. Tal fato somente ocorrerá se houver as informações necessárias disponibilizadas no sistema para que, com elas, os gestores, distribuidores de recursos, estejam atentos à realidade local. Em termos gerenciais, ao se pesquisar a caracterização dos condicionantes da distribuição de recursos e competências em unidades de saúde pública distribuídas espacialmente, novas investigações poderão apontar a adequação de estudo e possível implementação em outros tipos de organização e setor, juntamente com os seus fatores promotores e dificultadores específicos.

No entanto não se pode deixar de destacar a importante relação que existe entre as condições de trabalho dos agentes de saúde. Podendo-se destacar a existência de recursos e sua adequada aplicação no trabalho, com a própria condição de saúde e estresse de seus agentes. O trabalho de Bono, Glomb, Shen, Kim e Koch (2013) sugere que os eventos discretos positivos e negativos específicos nas condições de trabalho possuem potencial significativo nesse sentido.

A seguir, apresenta-se a fundamentação teórica considerando a Visão Baseada em Recursos, o Sistema de Informações Geográficas, o Sistema de Saúde no Brasil, destacando-se a Estrutura da Secretaria Municipal da Saúde de Curitiba, a Estrutura Organizacional da Secretaria Municipal da Saúde de Curitiba e da Unidade Municipal de Saúde da Família estudadas por este trabalho.

\section{Visão Baseada em Recursos}

A visão baseada em recursos tornou-se importante metodologia de análise comparativa das organizações. Por exemplo, em pesquisas internacionais, a investigação de Stankiewicz (2012) busca elaborar um modelo de competitividade entre fronteiras para organizações de saúde, também, utilizando a VBR. Seus resultados estão relacionados à competitividade de sistemas de saúde entre nações. 
Importante trabalho de Xia e Li (2013), sobre a teoria da dependência de recursos em organizações públicas, aproxima parcialmente este estudo da proposta em pauta quando procura explicar a dependência mútua entre as unidades organizacionais por meio das condições externas e internas da dependência de recursos de outros agentes governamentais. $\mathrm{O}$ estudo revela que a dependência mútua e o aumento do poder das subunidades ampliam a sua relevância no conjunto das unidades envolvidas em seu processo decisório.

No país, a pesquisa de Oliveira e Toda (2013) apresenta a Tecnologia da Informação (TI) e o Planejamento Estratégico (PE) como recursos valiosos para o desenvolvimento da competência hospitalar. Identifica carências e problemas relativos ao planejamento, à seleção e à implantação e ao uso da tecnologia da informação. Os resultados sugerem o quanto a gestão hospitalar precisa ser aprimorada, especialmente no tocante ao reconhecimento da TI como recurso valioso para o desenvolvimento de competências organizacionais e de inovações.

Ainda no Brasil, a pesquisa de Santos, Gonçalves e Figueiredo (2013) analisa o desempenho de municípios da região Sudeste na alocação de recursos na atenção básica da saúde, de 2007 a 2010 . Foi feita uma análise de cluster para agrupar os municípios semelhantes, bem como foram utilizados os índices de eficiência técnica produzidos pela metodologia de Data Envelopment Anaysis (DEA) para a análise de desempenho. Os resultados apontam que os escores de eficiência obtidos deixaram evidentes as disparidades na alocação de recursos, fato que poderia ser justificado na ausência de procedimentos de comparação relativa entre estes dados e o modelo adotado no país.

O estudo de Cobaito (2012) analisa a experiência de um Plano Diretor de Melhoria da Gestão Hospitalar utilizando a VBR nas ações dos diversos serviços prestados pelas áreas internas hospitalares. E comprova ser possível hospitais com natureza jurídica de Fundação sem fins lucrativos, através de melhorias nos arranjos organizacionais e práticas de gerenciamento de seus processos internos, enquanto recursos, serem convertidos em centros de maior eficácia e obterem o reconhecimento público. Como resultado, verificou-se ser possível a formulação de uma estratégia de sucesso no segmento de saúde hospitalar, fundamentada na visão baseada em recursos.

A seguir, destacam-se os fundamentos para a aplicação da abordagem da VBR de modo adaptado à análise em pauta, dessa maneira, procurando explicar as decisões entre a unidade de saúde destacada deste estudo e a gestão de recursos tangíveis e intangíveis em busca da eficiência no atendimento. Uma vez decididos, segundo Barney (1992, 1994, 1996), Barney e Hesterly (1996) e Wernerfelt (1984), os recursos são vinculados de forma semipermanente à organização, assim, não podem ser transferidos a outra sem custos e isso a capacita a conceber e executar estratégias de modo a obter e/ou manter certa posição em sua capacidade de gerar valor. Dessa forma, conforme observado neste trabalho, é importante que o sistema de distribuição de recursos na saúde possua critérios claramente definidos para a sua efetiva adequação às comunidades atendidas.

Como referência de análise deste sistema, seguem-se os indicadores adaptados radicalmente do modelo de Barney $(1992,1996)$ e sugeridos pelos autores. Os fatores propostos podem contribuir para a análise dos recursos em termos de fontes sustentáveis para o atendimento das necessidades da população que demanda serviços locais de saúde, como nas unidades de atendimento familiar, objeto desta pesquisa:

1. Disponibilidade: trata-se de um recurso existente em termos de quantidade e qualidade necessária.

2. Valioso: o recurso (pessoal, competências, edificações, material e medicamentos) apresenta ou não valor para atender as necessidades da população em conformidade com os incidentes críticos existentes na localidade.

3. Difíceis de serem substituídos: corresponde a quando uma unidade, que não possui determinado recurso, enfrenta custos sociais significativos até obtê-lo.

Dessa forma, tem-se como pressuposto que é possível constatar o grau de sustentabilidade no atendimento da população permeada pelo recurso distribuído (Tabela 1): 
Tabela 1

\section{Implicações Decisórias}

\begin{tabular}{ccccl}
\hline O Recurso é... & & & & \\
\hline $\begin{array}{c}\text { Possuído pela } \\
\text { Unidade }\end{array}$ & Disponibilidade & Valioso & $\begin{array}{c}\text { Difícil de ser } \\
\text { Substituído }\end{array}$ & Implicações para o atendimento \\
\hline Não & - & - & - & Impossibilidade de atendimento \\
Sim & Não & - & - & Dificuldade no atendimento \\
Sim & Sim & Não & - & Atendimento eventualmente adequado \\
Sim & Sim & Sim & Não & Atendimento adequado e valioso \\
Sim & Sim & Sim & Sim & $\begin{array}{l}\text { Atendimento adequado, valioso e socialmente } \\
\text { sustentável }\end{array}$ \\
\hline
\end{tabular}

Nota. Fonte: adaptado estrutural e conceitualmente de Barney, J. (1992). Integrating organizational behavior and strategy formulation research: a resource based analysis (p. 55). In P. Shrivastava, A. S. Huff, \& J. E. Dutton (Eds.), Advances in strategic management (Vol. 8, pp. 203-227). Greenwich: Jai Press.

De um modo mais amplo, os indicadores dispostos na Tabela 1 admitem a seguinte análise: quais recursos permitem atendimento da população em suas necessidades básicas de saúde, de modo adequado, valioso e sustentável? Isso se refere a atender as necessidades de saúde da população com os recursos que permitam atender necessidades que afetem uma determinada população nas demandas locais de modo efetivo, ou seja, que resolvam as questões médicas e contribuam com as contextuais.

A seguir, apresentam-se os fundamentos do Sistema de Informações Geográficas (SIG) que, aliados à VBR, representam as relações conceituais delineadas no problema deste trabalho.

\section{Sistemas de Informações Geográficas}

Segundo Câmara e Queiroz (2006), o termo SIG é aplicado para sistemas que realizam o tratamento computacional de dados geográficos e recuperam informações não apenas com base em suas características alfanuméricas, mas também através de sua localização espacial. A geometria e os atributos dos dados num SIG devem estar georreferenciados, isto é, localizados na superfície terrestre e representados numa projeção cartográfica. Para Cowen (1988), SIG é um sistema de apoio à decisão que envolve a integração de dados espacialmente referenciados, em um ambiente para resolução de problemas. Sintetizado, por Burrough e McDonnell (1998), como um conjunto de ferramentas para coletar, armazenar, recuperar, transformar e representar visualmente dados espaciais.

Pina (1998) destaca ser possível, com os SIG, entender o contexto geográfico e potencializar análises espaciais de dados desenvolvidas durante o planejamento, bem como combinar diferentes dados, tais como, renda, densidade demográfica, grau de instrução, saúde entre outros. A tecnologia de SIG pode trazer enormes benefícios devido à sua capacidade de manipular a informação espacial de forma precisa, rápida e sofisticada (Goodchild, 1992).

O SIG é o sistema mais adequado para a análise espacial de dados geográficos relacionados à saúde, por exemplo, por possibilitar ao gestor corporativo, aos secretários de saúde municipais e estaduais e aos gestores das unidades de atendimento associarem informações relativas às unidades distribuídas espacialmente.

Sempre que a decisão for referente à distribuição de recursos, entre as questões e problemas a serem resolvidos pelo sistema, haverá oportunidade para considerar a adoção do SIG. No caso das Unidades Municipais de Saúde (UMS), o onde é questionado em diversas situações, como, por exemplo: 
- Onde se localizam as áreas de maior densidade demográfica?

- Onde estão localizadas as unidades de saúde do município?

- Onde estão localizadas as gestantes, os hipertensos, o maior número de acidentes?

De acordo com documento do Ministério da Saúde (n.d.), os SIG em saúde devem ser integrados ao Departamento de Cartografia do Instituto Brasileiro de Geografia e Estatística (IBGE) no sentido de digitalizar as bases cartográficas com as informações geográficas e demográficas, a partir de endereço, de todas as regiões brasileiras no Cadastro de Segmentos de Logradouros por Setor Censitário via censo.

Em razão de a saúde ser resultante das condições alimentares, habitação, renda, meio ambiente, trabalho, transporte, saneamento, emprego, lazer, liberdade e acesso aos serviços de saúde via atendimento médico (Pina, 1998), o SIG pode permitir, com esses dados, importantes relações causais e a preocupação em não preestabelecer restrições ao relacionamento entre os dados. Assim, tornando mais consistentes as possibilidades entre a relação do SIG com as potencialidades da análise da VBR, possibilitando a identificação e a caracterização de relações decisórias indispensáveis para o atendimento da população.

\section{Sistema de Saúde no Brasil}

Dadas as características peculiares do sistema de saúde no Brasil, apresenta-se a seguir as principais características que compõem a estrutura de responsabilidade legal e de recursos de atendimento das populações distribuídas geograficamente.

De acordo com Dobashi, Brêtas e Silva (2011), até o final da década de 1980, as políticas de saúde do Brasil não abrangiam toda a população e estavam vinculadas ao sistema previdenciário, ou seja, ao Instituto Nacional de Previdência Social (INPS), tendo origem no governo Vargas, décadas de 1930 e 1940. De 1968 a 1974, o desenvolvimento econômico apresentou concentração de renda e degradação das condições de vida e saúde da população. Diante disso, nos anos 1970, aconteceram os movimentos sociais, cujo objetivo era resgatar os valores relacionados à cidadania, principalmente aqueles voltados ao setor de saúde.

Esses movimentos, junto com as agências internacionais, exerceram pressão sobre o governo Geisel, de tal forma que a política governamental rompeu com a lógica exclusiva da viabilidade econômica, incluindo-se o setor social, em 1974, no II Plano Nacional de Desenvolvimento (PND), responsável pela criação do PIS-PASEP, ampliação da cobertura de previdência entre outros, e destacando-se como avanços a incorporação das Secretarias de Saúde e dos Hospitais Universitários para atendimento de urgência aos previdenciários por meio do Plano de Pronta Ação, convênios globais (1974).

Em 1977, foi criado o Instituto Nacional de Assistência Médica da Previdência Social (INAMPS). O Inamps apresentava problemas relacionados à centralização das decisões financeiras e operacionais, redes de atendimento não integradas, privatização dos serviços de saúde, entre outros, os quais deram continuidade às transformações institucionais. Então, em 1979, foi criado o Programa de Interiorização das Ações de Saúde e Saneamento (PIASS).

Em 1980, realizou-se a VII Conferência Nacional de Saúde e elaboração do PREV-SAÚDE, em 1982, a criação do Conselho Nacional de Segurança Pública (CONASP) e, em 1987, foi criado o Sistema Unificado e Descentralizado de Saúde (SUDS), consolidando o movimento de reforma sanitária a partir do qual surgiram projetos municipais de organização dos sistemas locais de saúde em Campinas (SP), Caruaru (PE), Montes Claros (MG); movimento dos trabalhadores de saúde: Centro Brasileiro de Estudos de Saúde (CEBES), em 1976, e Associação Brasileira de Pós-Graduação em Saúde Coletiva 
(ABRASCO), em 1979; encontros de Secretarias Municipais de Saúde e, em 1982, foi criado o Conselho Nacional de Secretários de Saúde (CONASS).

Andrade (2001) explica que, ao estabelecer a saúde como direito de todos e dever do Estado, o princípio central da reforma sanitária passou a ser garantido pela Constituição Federal, promulgada em 05 de outubro de 1988, e responsável pela regulamentação do Sistema Único de Saúde (SUS), que define:

As ações e serviços públicos de saúde integram uma rede regionalizada e hierarquizada e constituem um sistema único, organizado de acordo com as seguintes diretrizes:

I - descentralização, com direção única em cada esfera de governo;

II - atendimento integral, com prioridades para as atividades preventivas, sem prejuízo dos serviços assistenciais;

III - participação da comunidade. (Noronha, Santos, \& Pereira, 2010, p. 155).

O SUS é um modelo redistributivo, inspirado nas premissas igualitárias do Estado de bem-estar social europeu (Ocké-Reis, 2011). Para Nunes e Queiroz (2007), o SUS é um dos maiores sistemas públicos de saúde do mundo. É um sistema porque é formado por várias instituições dos três níveis de governo, União, Estados e Municípios e pelo setor privado por meio de contrato administrativo ou convênio para a realização de serviços e saúde, como se fosse um corpo único. Dessa forma, o setor privado, quando contratado pelo SUS, deve atuar como se fosse público, a sua participação é regulamentada por disposições e princípios gerais de atenção à saúde, podendo participar de forma complementar ao SUS, segundo suas diretrizes. É único, devido a sua atuação em todo território nacional ser pautada na mesma filosofia, sendo organizado com a mesma lógica. É universal, deve atender a todos sem distinção e conforme as suas necessidades. É integral, a saúde deve ser tratada como um todo, ou seja, as ações de saúde devem ser voltadas simultaneamente ao indivíduo e à comunidade, tanto para a prevenção como para o tratamento. Garante a equidade, deve oferecer os recursos de saúde de acordo com as necessidades de cada um. É descentralizado, todas as ações e serviços que atendem a população de um município devem ser municipais; as que servem e alcançam vários municípios devem ser estaduais e as dirigidas a todo território nacional devem ser federais. O SUS tem um gestor único em cada esfera de governo. De acordo com Andrade (2001), em agosto de 1996, o Ministério da Saúde edita a portaria 1.742, que instituiu a Norma Operacional Básica - SUS 01/1996, que tem como tema principal: Gestão plena com responsabilidade pela saúde do cidadão, buscando construir a plena responsabilidade do poder público municipal sobre a gestão de um sistema de saúde e não apenas sobre a prestação de serviços de saúde. Foram criadas duas categorias de gestão municipal: (a) Gestão Plena da Atenção Básica, que credencia o gestor municipal para elaborar a programação municipal dos serviços básicos, gerir unidades ambulatoriais próprias e contratar, controlar, auditar e pagar aos prestadores de serviços procedimentos e ações de assistência básica; (b) Gestão Plena de Sistema Municipal, que propicia ao gestor municipal a possibilidade de elaborar toda a programação municipal, incluída a de prestação de assistência ambulatorial especializada e hospitalar, conferindo aos municípios a ampliação de suas responsabilidades voltadas às necessidades da população (Nunes \& Queiroz, 2007).

Logo, a NOB-SUS 01/96 introduziu a visão de SUS municipal, que procura fortalecer o sistema local de saúde integrando uma rede regionalizada, hierarquizada e disciplinada segundo subsistemas em cada município. Segundo Nunes (2007), essa norma veio aperfeiçoar a gestão de serviços de saúde e a própria organização do sistema, pois reafirma os princípios constitucionais ao definir que o município é o responsável, em primeira instância, pela situação de saúde de sua população, organizando os serviços que estão sob sua gestão e/ou participando na construção do acesso aos demais serviços.

Conforme citam Nunes e Queiroz (2007), os serviços de saúde devem estar organizados de maneira regionalizada, uma vez que nem todos os municípios conseguem atender a todas as demandas e todo o tipo de problemas de saúde. Segundo os autores, a organização desses serviços precisa ser hierarquizada, ou seja, questões menos complexas de saúde devem ser atendidas nas Unidades Básicas. Nas questões especificas devem ser encaminhadas para as Unidades de Atendimento Especializado. Um nível de atendimento mais complexo deve ser encaminhado ao Hospital Geral, chegando até o Hospital 
Especializado. Observa-se, portanto, que cada um desses níveis demanda recursos e competências de volume e complexidade diferenciada para o seu adequado atendimento.

O SUS tem de ser eficaz e eficiente através da prestação de serviços de qualidade, eliminando-se desperdícios e aplicando-se os recursos da melhor maneira possível. Seu financiamento compete às três esferas do governo e é custeado por meio de recursos financeiros providos do Tesouro, destacando-se como principais fontes de financiamento federal a contribuição sobre o faturamento (COFINS), contribuição sobre lucro líquido, fontes fiscais voltadas à cobertura de despesas com pessoal e encargo social e contribuição provisória sobre movimentação (CPMF) (Nunes, 2007).

A atenção básica é o primeiro nível de atenção em saúde e deve ser ofertada por todos os municípios, com qualidade e suficiência para a população. Contempla ações estratégicas mínimas que são necessárias para a atenção adequada aos problemas de saúde que ocorrem com mais frequência na maior parte do Brasil. Consiste num montante de recursos financeiros destinados, portanto, a ações desse nível. Em 2001, passou a ser chamado de PAB Ampliado (Nunes, 2007). O PSF é atualmente denominado Estratégia de Saúde da Família e foi oficializado pelo Ministério da Saúde/Fundação Nacional de Saúde em março de 1994 (Andrade, 2001).

\section{Estrutura da Secretaria Municipal da Saúde de Curitiba}

De acordo com informações fornecidas pelo Instituto de Pesquisa e Planejamento Urbano de Curitiba (IPPUC, 2013), a rede de saúde, considerando a dependência administrativa pública municipal, conta atualmente com:

. 50 Unidades Básicas de Saúde;

. 54 Unidades Básicas com Estratégia de Saúde da Família;

. 4 Unidades de Saúde Complexas;

. 8 Unidades Especializadas;

. 1 Unidade de Saúde 24 horas;

. 5 Unidades de Saúde - Residência Terapêutica;

. 7 Unidades de Saúde - Urgências Médicas;

. 14 Centros de Atendimento Psicossocial (CAPS);

. 7 CMUM;

. 2 Hospitais Gerais e Maternidade, e

. 1 Laboratório de Análises Clínicas.

Nota-se, portanto, a complexa rede de atendimento à população dessa Secretaria de Saúde e as exigências para o atendimento adequado e sustentável de suas diferentes unidades, com demandas e recursos específicos. A seguir, apresenta-se a estrutura organizacional da secretaria e a caracterização do caso em estudo.

\section{Estrutura organizacional da secretaria municipal da saúde de Curitiba}

A Secretaria Municipal da Saúde de Curitiba é composta pelo Conselho Municipal da Saúde, pelo Gabinete (2 Superintendências, 6 Centros e 9 Distritos Sanitários) e 4 Núcleos de Apoio (Financeiro, 
Administrativo, Jurídico e de Recursos Humanos). Os Centros são denominados de Informação em Saúde, Saúde Ambiental, Epidemiologia, Assistência à Saúde, de Controle, Avaliação e Auditoria e Sistema de Urgência e Emergência de Curitiba (SUEC). Os Distritos Sanitários são compostos pelas Unidades de Saúde, Coordenação de Informação, Coordenação de Assistência e Coordenação de Vigilância à Saúde.

\section{Unidade municipal de saúde Pinheiros/estratégia de saúde da família}

A Unidade Municipal de Saúde Pinheiros/Estratégia de Saúde da Família (UMS Pinheiros ESF), unidade de análise desta pesquisa, está localizada na Rua Joanna Emma Dalpozzo Zardo, 370, Bairro Jardim Pinheiros, Distrito Sanitário de Santa Felicidade, município de Curitiba (PR), inaugurada em 10/12/1985. Na Tabela 2, foram relacionadas as conferências e os respectivos temas abordados.

Tabela 2

Conferências da UMS Pinheiros ESF

\begin{tabular}{|c|c|c|}
\hline Conferência & Ano & Tema \\
\hline $1^{\mathrm{a}}$ & 1991 & Formado o $1^{\circ}$ Conselho Local de Saúde \\
\hline $2^{\mathrm{a}}$ & 1997 & Saúde Mental \\
\hline $3^{\mathrm{a}}$ & 1999 & $\begin{array}{l}\text { Meio Ambiente e Saúde no III Milênio } \\
\text { 21/03/2000 - Inclusão do } 1^{\circ} \text { ACS }\end{array}$ \\
\hline $4^{\mathrm{a}}$ & 2001 & $\begin{array}{l}\text { Pacto Pela Vida - Venha Participar } \\
\text { 10/12/2001 - Passou de US para Unidade de Saúde da Família }\end{array}$ \\
\hline $5^{\mathrm{a}}$ & 2003 & $\begin{array}{l}\text { Construindo um Sonho em Saúde Mental } \\
\text { 29/07/2004 - Reinauguração da US após ampliação da estrutura predial }\end{array}$ \\
\hline $6^{\mathrm{a}}$ & 2005 & $\begin{array}{l}20 \text { Anos Conquistando Saúde e Qualidade de Vida } \\
\text { 27/10/2005 - Comemoração dos } 20 \text { anos da US }\end{array}$ \\
\hline $7^{\mathrm{a}}$ & 2007 & Adolescência Bem Vivida \\
\hline $8^{\mathrm{a}}$ & 2009 & Qualidade de Vida \\
\hline $9^{\mathrm{a}}$ & 2011 & A Importância do Autocuidado \\
\hline
\end{tabular}

Nota. Fonte: editada pelos autores a partir dos dados fornecidos pela S. R. B. Rustick (comunicação pessoal, 6 de março de 2012 - dados extraídos da Secretaria Municipal da Saúde de Curitiba. (2009). Plano municipal de saúde: $2010 / 2013$. Recuperado de http://www.saude.curitiba.pr.gov.br/images/institucional/arquivos/planos/plano_001.pdf).

\section{Síntese Teórica de Referência}

A Figura 1 ilustra um modelo que aproxima a Visão Baseada em Recursos (VBR), com ênfase na divisão dos recursos proposta por Barney (1996), Barney e Hesterly (1996), Grant (1991) e Kay (1996), o Sistema de Informações Geográficas (SIG) proposto Burrough e McDonnell (1998) e a Unidade Municipal de Saúde (UMS) proposta pelo SUS. É possível verificar que as três referências teóricas se conectam através da localização geográfica por meio de suas informações como base para a definição dos recursos necessários para os atendimentos de cada uma das Unidades Municipais de Saúde, conforme observado anteriormente. 


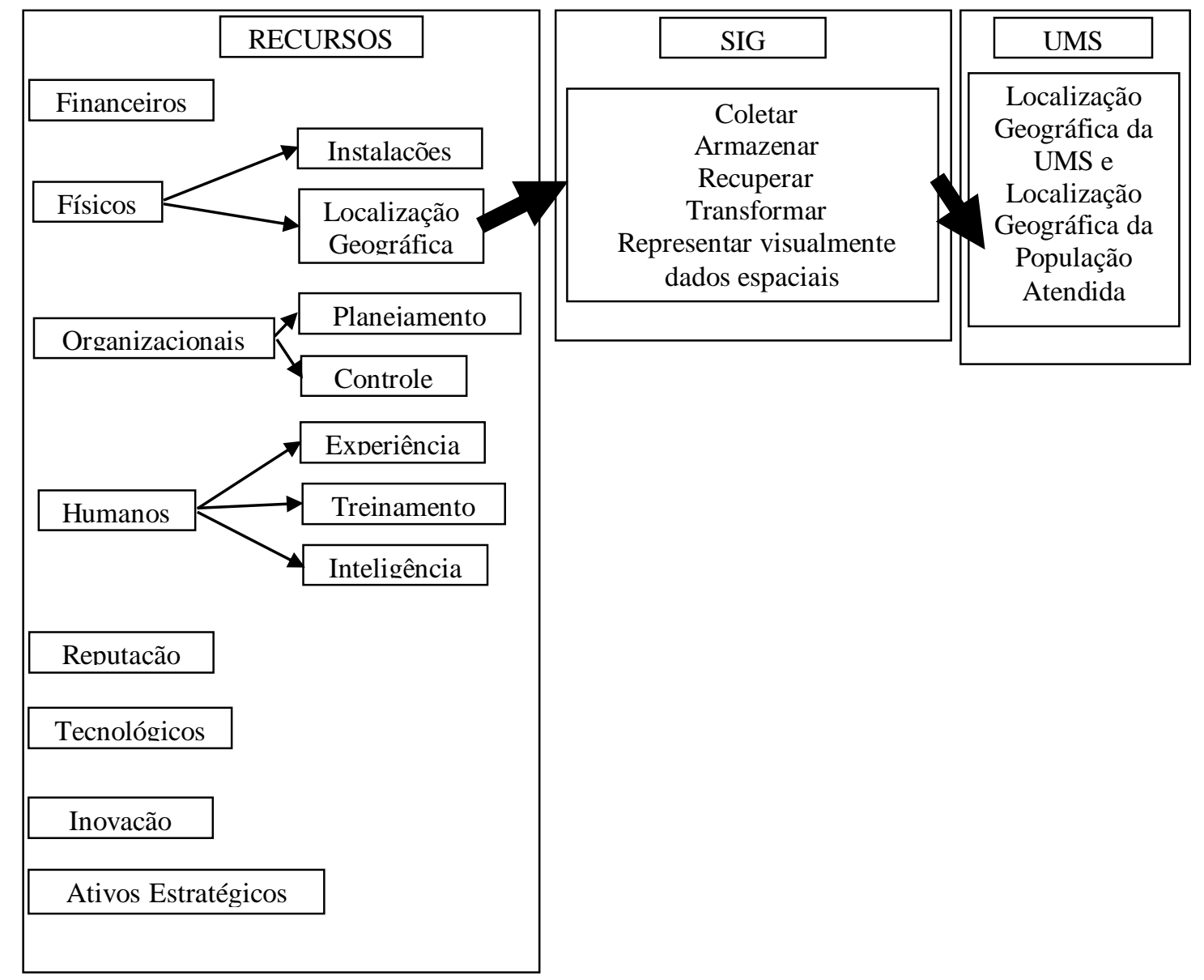

Figura 1. Bases Teóricas de Referência com VBR, SIG e UMS.

Fonte: Elaborado pelos autores.

\section{Metodologia}

Esta pesquisa apresenta o desenvolvimento de estudo de caso, com perspectiva qualitativa, aplicado na Unidade Municipal de Saúde Pinheiros Estratégia de Saúde da Família (UMS Pinheiros ESF).

No que diz respeito aos procedimentos para a coleta de dados referente à construção do modelo, foram utilizados os seguintes recursos: pesquisa documental nos instrumentos legais, atas, relatórios e material disponibilizado na mídia, pertinentes aos órgãos formuladores das políticas assistenciais, mais precisamente os editados pelo Ministério da Saúde, Secretaria de Saúde do Paraná e Secretaria Municipal da Saúde de Curitiba. Foram realizadas entrevistas com o Secretário Municipal de Saúde, o Superintendente e o Gestor responsáveis pela Unidade de Saúde e o Coordenador de Vigilância à Saúde. Foram entrevistados também quatro servidores, sendo dois médicos e dois atendentes e nove pacientes usuários regulares da Unidade pesquisada. As entrevistas locais foram acompanhadas de observação não participante durante seis semanas, no período de março de 2012, e replicadas de janeiro a fevereiro de 2013. As observações foram relevantes para entender a relação entre o uso dos recursos existentes na unidade, sua aplicação e a percepção dos profissionais atendentes e usuários. As entrevistas, observação e a análise dos documentos permitiram identificar o SIG existente e sua aplicação como referência para a distribuição dos recursos do sistema para as unidades de saúde, mais especificamente para a Unidade em estudo. 
No Instituto de Pesquisa e Planejamento Urbano de Curitiba (IPPUC), foi adquirida a base cartográfica digital do município de Curitiba (PR), edição 2005, em formato de arquivo com extensão shapefile necessária à elaboração do SIG, bem como realizada consulta ao Departamento de Geoprocessamento.

Dessa forma, a fonte de dados classifica-se tanto como primária, por ser obtida por meio de contato direto com a Autoridade Sanitária Local da UMS Pinheiros ESF e com o Coordenador de Geoinformação do IPPUC, quanto como secundária, por ser obtida junto a documentos produzidos no âmbito do Sistema SUS e IPPUC.

Compõem a metodologia, a análise do desenvolvimento dos condicionantes da gestão de recursos e competências, bem com a análise do desenvolvimento do SIG.

\section{Análise dos Condicionantes da Gestão de Recursos por meio do SIG}

Em consulta ao Instituto de Pesquisa e Planejamento Urbano de Curitiba (IPPUC), em 04/01/2012, foi informado que o mesmo possui georreferenciadas as 107 áreas de abrangência das UMS, que foram fornecidas para o desenvolvimento da pesquisa (Figura 2). As áreas, microáreas e os usuários das UMS não constam na base cartográfica digital do IPPUC. Diante disso, a partir do mapa analógico fornecido pela UMS Pinheiros ESF, foi realizada a vetorização das áreas (Figura 3) e microáreas (Figura 4) na base cartográfica digital de Curitiba. Foi, então, realizado o georreferenciamento da sede da UMS Pinheiros ESF, bem como das 57 gestantes cadastradas até o dia 24/02/2012 (Figura 5), usuárias dessa unidade de saúde. Para as atividades de vetorização e georreferenciamento foi utilizado o software ArcGIS 9.3, desenvolvido pela empresa ESRI.

A identificação e a caracterização dos condicionantes da distribuição e da gestão dos recursos foram individuadas principalmente por meio das entrevistas e análise documental, cuja triangulação permitiu a validação interna e externa dos dados coletados.

De acordo com o Instituto Brasileiro de Geografia e Estatística (2010), a população para a UMS Pinheiros ESF, corresponde a 13.434 habitantes. Dessa população, $40 \%$ são dependentes do SUS, caso esse percentual fosse igual a $100 \%$, seriam necessárias providências para ampliar a rede. É possível constatar também que o percentual de SUS dependente para as Unidades de Saúde Bom Pastor (40\%), Butiatuvinha (60\%), Campina do Siqueira (20\%), Jardim Gabineto (50\%), Nova Orleans (50\%), Santa Felicidade (40\%), Santos Andrade (50\%), São Braz (50\%) e União das Vilas (50\%) não atingem 100\%. Com base nesses dados, os gestores sugerem que a rede não precisa, no momento, ser ampliada. Bem como a Unidade em análise.

Todas as UMS realizam os mesmos programas de acompanhamento: Programa Mãe Curitibana, Programa Saúde da Criança, Programa de Controle de Hipertensão/Diabetes, Programa DST/Aids, Programa de Saúde Bucal, Programa de Saúde Mental, Programa de Saúde do Adolescente, Programa da Mulher, Tuberculose, Hanseníase, todas as doenças de notificação obrigatórias (ex: sarampo, rubéola). Cada UMS trabalha de modo independente uma da outra, mas todas devem atingir os objetivos relacionados ao atendimento populacional previamente traçados, como, por exemplo, cobertura vacinal e atendimento a gestantes. 


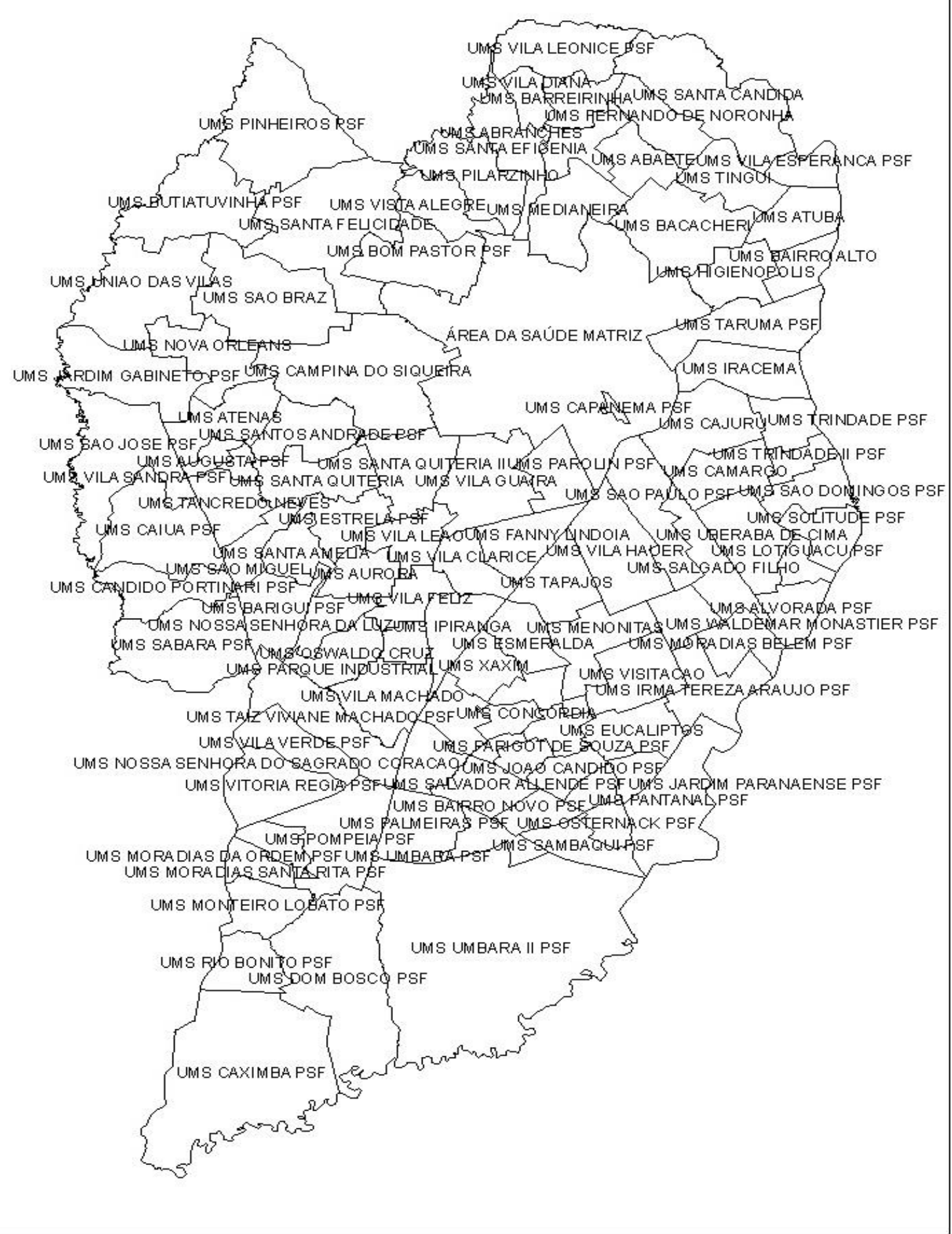

Figura 2. Áreas de Abrangência das UMS (Curitiba/PR).

Na Figura 2, os limites correspondem as 107 áreas de abrangência das Unidades Municipais de Saúde.

Fonte: editada pelos autores a partir do Instituto de Pesquisa e Planejamento Urbano de Curitiba. (2013, dezembro 16). Mapa base. Recuperado de http://ippuc.org.br/geodownloads/geo.htm 


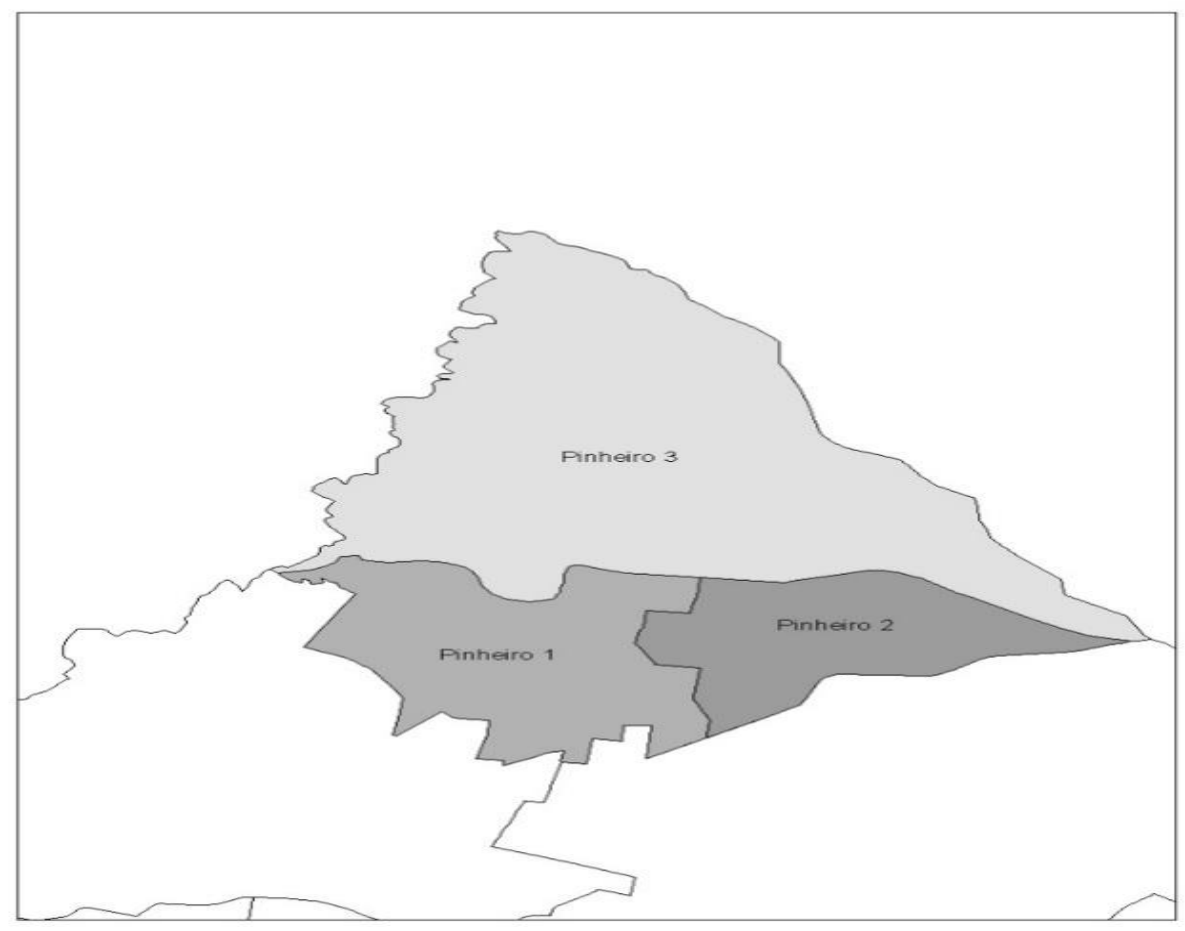

Figura 3. Áreas da UMS Pinheiros ESF (Curitiba/PR).

Na Figura 3, os limites correspondem as 3 áreas de abrangência da Unidade Municipal de Saúde Pinheiros ESF.

Fonte: editada pelos autores a partir do Instituto de Pesquisa e Planejamento Urbano de Curitiba. (2013, dezembro 16). Mapa base. Recuperado de http://ippuc.org.br/geodownloads/geo.htm

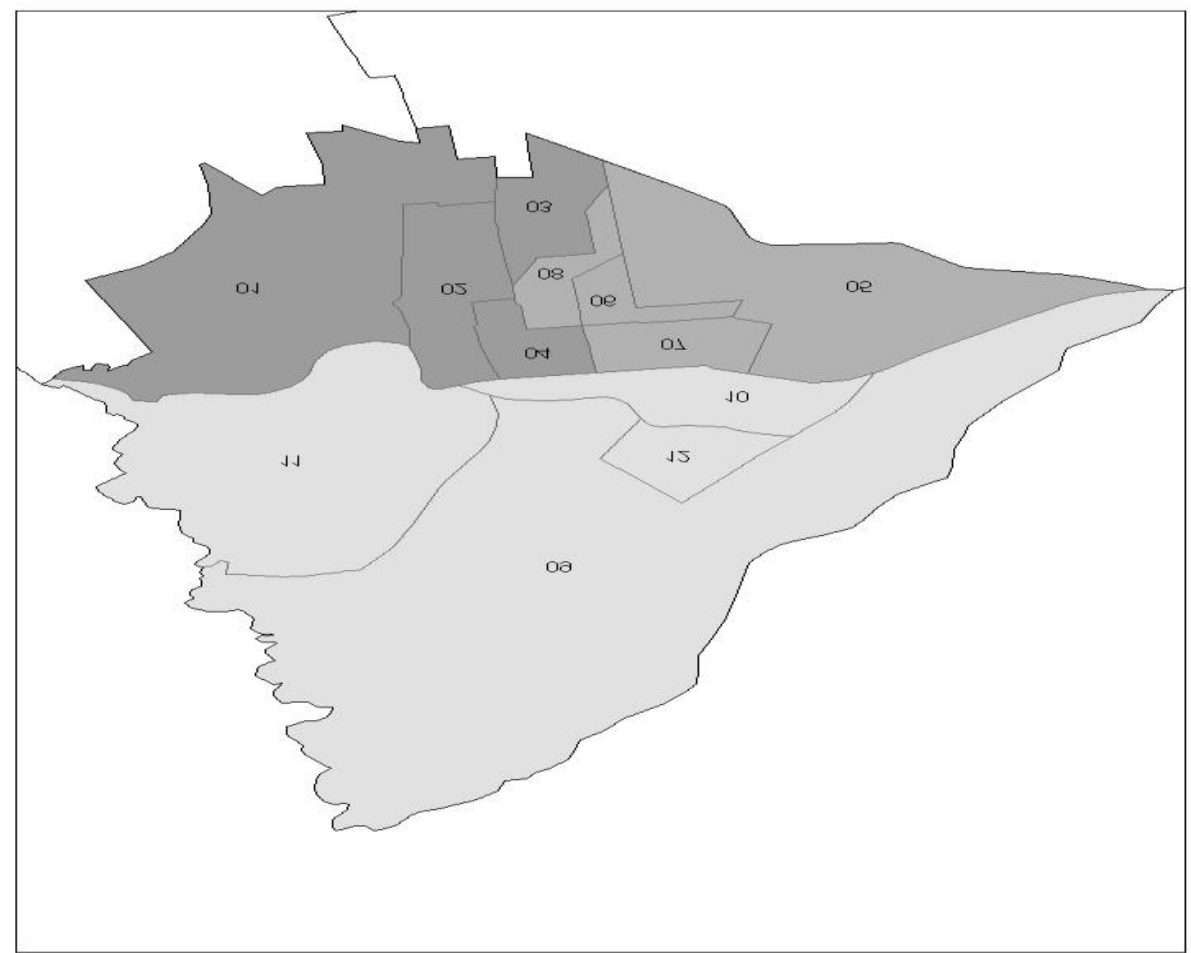

Figura 4. Microáreas da UMS Pinheiros ESF (Curitiba/PR).

Na Figura 4, os limites correspondem às 12 microáreas da Unidade Municipal de Saúde Pinheiros ESF.

Fonte: editada pelos autores a partir do Instituto de Pesquisa e Planejamento Urbano de Curitiba. (2013, dezembro 16). Mapa base. Recuperado de http://ippuc.org.br/geodownloads/geo.htm 


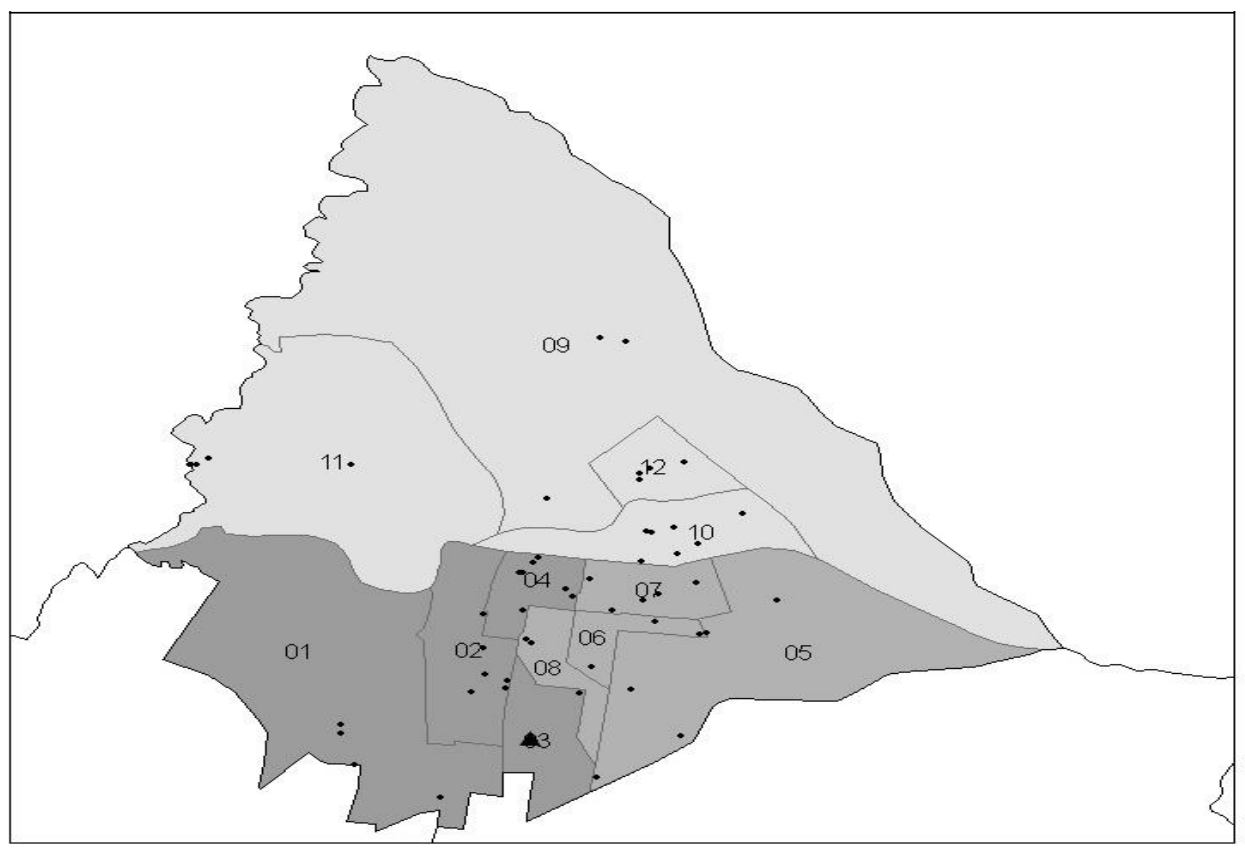

Figura 5. Gestantes da UMS Pinheiros ESF (Curitiba/PR).

Na Figura 5, estão representadas as 57 gestantes até 24/02/2012, de acordo com os limites correspondentes às 12 microáreas da Unidade Municipal de Saúde Pinheiros ESF.

Fonte: editada pelos autores a partir do Instituto de Pesquisa e Planejamento Urbano de Curitiba. (2013, dezembro 16). Mapa base. Recuperado de http://ippuc.org.br/geodownloads/geo.htm

Os trabalhos das UMS são desenvolvidos por meio de metas estabelecidas no Planejamento Orçamentário Anual (POA), que são calculadas e monitoradas a cada trimestre. Como exemplo, podese citar especificamente o atendimento a gestantes vinculadas ao Programa Mãe Curitiba até o $4^{\circ}$ mês de gestação pela UMS. Gestantes atendidas no período representam as metas atingidas e relacionadas à população demandante. Gestantes acima do $4^{\circ}$ mês de gravidez, normalmente, dirigem-se a UMS quando têm conhecimento da não cobertura de parto pelo plano de saúde e optam pelo SUS, nestes casos, a UMS faz o acompanhamento, mas não configura como meta. A UMS Pinheiros apresenta como Meta Pactuada Anual em 2012, 92 gestantes. O número de inscrições no Programa Mãe Curitiba, totalizou 115, ou seja, um número superior a 92 gestantes, igual a 23. Das 115 gestantes inscritas, 99 realizaram inscrição até o $4^{\circ}$ mês de gestação, 16 gestantes não (S. R. B. Rustick, comunicação pessoal, 6 de março de 2012).

Existem situações complexas como, por exemplo, ataque cardíaco, parto, necessidade de exames complementares, entre outras, que não competem ao atendimento das UMS, mas são realizados enquanto primeiro atendimento emergencial. Nesses casos é acionado o Serviço de Atendimento Móvel de Urgência (SAMU) ou, dependendo do caso, ambulância comum para fazer o encaminhamento ao Centro Municipal de Urgência Medica (CMUM), que realiza a transferência para os hospitais.

Os limites das áreas de abrangência das UMS são definidos por setor censitário (IBGE, 2010) e indicados no SIG municipal, como apoio ao atendimento das instruções do Ministério da Saúde. Inclusive em suas áreas e microáreas, de acordo com o número da população, para que fiquem equivalentes na distribuição dos recursos. A UMS Pinheiro ESF é dividida em três áreas: Pinheiro 1, Pinheiro 2 e Pinheiro 3, cada uma com médico, odontólogo, técnico em higiene bucal (THB), auxiliar de consultório dental (ACD) e enfermeiro. Cada uma das áreas é dividida em quatro microáreas, cada uma com agente comunitário de saúde (ACS) e auxiliar de enfermagem (Tabela 3) e mais seis profissionais administrativos e do quadro de atendimento direto. 
Tabela 3

Área e Microárea da UMS Pinheiros ESF

\begin{tabular}{|c|c|c|c|}
\hline Área & Equipe & Microárea & Equipe \\
\hline \multirow[t]{9}{*}{ Pinheiro 1} & 1 - médico & 1 & $1-\mathrm{ACS}$ \\
\hline & & & 1 - aux. enfermagem \\
\hline & 1 - odontóloga & 2 & $1-\mathrm{ACS}$ \\
\hline & & & 1 - aux. enfermagem \\
\hline & $1-\mathrm{THD}$ & 3 & $1-\mathrm{ACS}$ \\
\hline & & & 1 - aux. enfermagem \\
\hline & $1-\mathrm{ACD}$ & 4 & $1-\mathrm{ACS}$ \\
\hline & & & 1 - aux. enfermagem \\
\hline & 1 - enfermeiro & - & - \\
\hline \multirow[t]{9}{*}{ Pinheiro 2} & 1 - médico & 5 & $1-\mathrm{ACS}$ \\
\hline & & & 1 - aux. enfermagem \\
\hline & 1 - odontóloga & 6 & $1-\mathrm{ACS}$ \\
\hline & & & 1 - aux. enfermagem \\
\hline & $1-\mathrm{ACD}$ & 7 & $1-\mathrm{ACS}$ \\
\hline & & & 1 - aux. enfermagem \\
\hline & $1-\mathrm{ACD}$ & 8 & $1-\mathrm{ACS}$ \\
\hline & & & 1 - aux. enfermagem \\
\hline & 1 - enfermeira & - & - \\
\hline \multirow[t]{9}{*}{ Pinheiro 3} & 1 - médica & 9 & $1-\mathrm{ACS}$ \\
\hline & & & 1 - aux. enfermagem \\
\hline & 1 - odontólogo & 10 & $1-\mathrm{ACS}$ \\
\hline & & & 1 - aux. enfermagem \\
\hline & $1-\mathrm{THD}$ & 11 & $1-\mathrm{ACS}$ \\
\hline & & & 1 - auxiliar enfermagem \\
\hline & $1-\mathrm{ACD}$ & 12 & $1-\mathrm{ACS}$ \\
\hline & & & 1 - aux. enfermagem \\
\hline & 1 - enfermeira & - & - \\
\hline
\end{tabular}

Nota. Fonte: S. R. B. Rustick (comunicação pessoal, 6 de março de 2012).

Além dos profissionais relacionados na Tabela 3, compõem a equipe 1 - Autoridade Sanitária Local (ASL), 1 - agente administrativo, 1 - fisioterapeuta, 1- farmacêutico, 1 - psicólogo e 1 nutricionista. O quantitativo de pessoal não é igual para todas as UMS. As UMS com denominação Estratégia de Saúde da Família têm como diferencial, em relação à Unidade de Saúde Básica, além da carga horária por funcionário igual a 40 horas semanais, visitas domiciliares para acamados.

Segundo dados das entrevistas, por unanimidade, o número e o perfil de qualificação e competências do pessoal da UMS Pinheiros ESF são suficientes para atender a população. Cada um tem a sua função no atendimento das demandas, tanto em termos da adequação quanto valoração. A ASL planeja e delega as tarefas, emite relatórios para a Unidade Regional e é responsável pela parte administrativa e burocrática. Quanto à qualificação do pessoal, a Secretária Municipal da Saúde propicia treinamento aos funcionários das UMS. Os treinamentos e atualização são sistematizados pelo 
planejamento e pelos incidentes críticos de cada uma das localidades. A ASL local recebe o número de vagas e indica o servidor cujo cargo está diretamente relacionado à demanda. Os treinamentos são vistos pela equipe de forma satisfatória, mais por sua abrangência do que por sua especificidade. Em Curitiba, quase todas UMS possuem a mesma estrutura física e equipamentos, em porte e especificidade de acordo com os programas comuns a todas as unidades. Não há equipamentos direcionados especificamente a determinados incidentes condicionantes espaciais, tais como condições de saneamento, acidentes de trânsito. Entretanto observa-se preocupação com indicadores populacionais específicos como os relacionados ao número de gestantes já citado.

Destaca-se, pelas entrevistas e observações, que os recursos medicamentos, físicos, organizacionais, humanos, reputação e equipamentos são adequadamente distribuídos pelos dados censitários e de atendimento. Desde 18/01/2012, as UMS passaram a fazer uso de um sistema voltado à saúde denominado E-saúde, que substituiu o antigo sistema de prontuário. O novo sistema apresenta como principal vantagem a interligação com as demais UMS, como também com os hospitais e as clínicas conveniadas ao SUS. O sistema E-saúde ainda se encontra em fase de aperfeiçoamento, mas certamente será importante instrumento para a composição do SIG com a necessidade dos recursos de cada uma das unidades de saúde.

Importante destacar que o SIG não é utilizado especificamente pela UMS, apenas para as decisões da Secretaria de Saúde. O seu uso poderia colaborar, significativamente, com as microdecisões locais, aperfeiçoando o atendimento relacionado às necessidades de saúde mais específicas, para além daquelas previstas previamente pelo sistema e que dizem respeito ao atendimento massificado, como o da gestante e da tuberculose. Deixam de ser apontados dados fundamentais da população como a localização de incidentes críticos locais, tais como doenças em crianças em idade escolar, questões de saneamento, entre outras problemáticas. Esses condicionantes poderiam prover informações relevantes da saúde populacional local. Representando espacialmente as unidades de saúde, suas áreas de abrangência, bem como as condições de saúde da população atendida em termos específicos e relacionada aos condicionantes locais. No sistema E-saúde, em aperfeiçoamento, em termos locais da UMS, é possível, para o momento, visualizar apenas a rua correspondente ao endereço do usuário.

São utilizados instrumentos que possibilitam saber o grau de satisfação da população com os serviços prestados pelas UMS. A Secretaria de Saúde aplica pesquisa de satisfação dos usuários anualmente por telefone. Com base nos resultados e considerando que o nível de satisfação esteja aquém do desejado, a SMS encaminha relatório para cada distrito sanitário, informando com os indicadores dos itens de cada UMS e seu posicionamento em relação às unidades vinculadas à Autoridade Sanitária Local (ASL).

Como atividades diretamente vinculadas aos recursos experiência e competências, destaca-se o projeto de troca de experiências ente as UMS, que vem acontecendo há dois anos. Os vários usuários da secretaria apresentam programas e eventos e seus resultados em um encontro anual e, segundo os entrevistados de nível gerencial, têm apresentado resultados importantes em termos de aprendizagem, de colaboração e construção de uma linguagem comum.

\section{Síntese dos Resultados}

A partir da análise do desenvolvimento dos condicionantes da gestão de recursos e competências foi elaborada a Tabela 4, conforme os conceitos de Barney (1996), Grant (1991) e Kay (1996). Nela estão relacionados os recursos organizacionais e físicos, tecnologia, reputação, inovação, capital humano e ativo estratégico das Unidades Municipais de Saúde em Curitiba e da Unidade Municipal de Saúde Pinheiros/Estratégia de Saúde da Família. 
Tabela 4

Recursos e Competências da UMS Pinheiros ESF

\begin{tabular}{|c|c|c|c|}
\hline Recursos & Descrição & UMS em Curitiba & UMS Pinheiros ESF (Curitiba) \\
\hline Organizacional & $\begin{array}{l}\text { Estrutura formal } \\
\text { da UMS: relação } \\
\text { com as demais e } \\
\text { relação entre os } \\
\text { funcionários da } \\
\text { UMS Pinheiros } \\
\text { ESF. }\end{array}$ & $\begin{array}{l}\text { O total de UMS atende a } \\
\text { população como um todo nos } \\
\text { mesmos programas de } \\
\text { acompanhamento. Cada uma } \\
\text { trabalha de modo independente, } \\
\text { mas todas devem atingir as metas } \\
\text { estabelecidas pelos programas } \\
\text { comuns. }\end{array}$ & $\begin{array}{l}\text { A ASL planeja e delega tarefas, emite } \\
\text { relatórios, é responsável pela parte } \\
\text { administrativa e burocrática. Os } \\
\text { demais funcionários exercem sua } \\
\text { função dentro do estabelecido pela } \\
\text { SMS. Para o pessoal que ocupa o } \\
\text { mesmo cargo, o trabalho é realizado } \\
\text { por meio de escala, sendo divididas } \\
\text { todas as funções que o cargo } \\
\text { demanda. }\end{array}$ \\
\hline
\end{tabular}

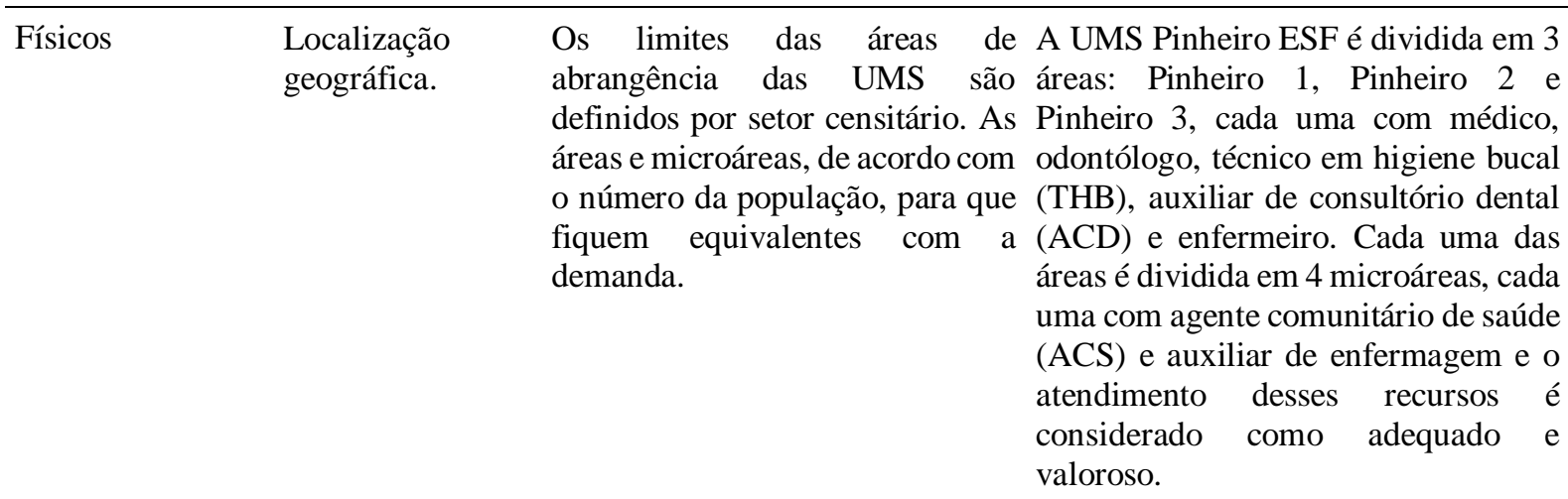

Estrutura física. Quase todas UMS possuem a Os recursos recepção, sala mesma estrutura física, algumas administrativa, consultórios, inalação, possuem o espaço saúde para sala de vacina, sala de curativo, sala atendimento da população. para coleta de exames laboratoriais, sala ginecológica, salas de enfermagem, consultório odontológico e farmácia são considerados adequados.

Desde 18/01/2012, as UMS passaram a fazer uso do novo sistema voltado à saúde, denominado E-saúde, que substituiu o antigo sistema de prontuário. As UMS não fazem uso de Sistemas de Informações Geográficas (SIG) para representar espacialmente as unidades de saúde, suas áreas de abrangência, bem como a população atendida.

Esses e os demais equipamentos destinados aos atendimentos dos programas são considerados adequados.

\begin{tabular}{lll}
\hline Reputação & $\begin{array}{l}\text { Satisfação da } \\
\text { população. }\end{array}$ & $\begin{array}{l}\text { São utilizados instrumentos que possibilitam saber o grau de satisfação da } \\
\text { população com os serviços prestados pelas UMS. É aplica pesquisa de } \\
\text { satisfação do usuário. A reputação é considerada adequada e valorosa. }\end{array}$ \\
\hline Inovação & $\begin{array}{l}\text { Atividade } \\
\text { inovadora. }\end{array}$ & $\begin{array}{l}\text { Como atividade inovadora desenvolvida pelas UMS, destaca-se o projeto } \\
\text { de troca de experiências, que vem acontecendo há dois anos. Atividade } \\
\text { essa considerada adequada e valorosa, com grande potencial de } \\
\text { sustentabilidade. }\end{array}$
\end{tabular}

Continua 


\section{Tabela 4 (continuação)}

\begin{tabular}{|c|c|c|}
\hline Recursos & Descrição & UMS Pinheiros ESF (Curitiba) \\
\hline Capacidade & & $\begin{array}{l}\text { A SMS propicia treinamento aos funcionários das UMS. Os treinamentos } \\
\text { ocorrem paulatinamente, com base em cursos de atualização. Também } \\
\text { existem cursos ofertados por instituições e universidades, assim, o } \\
\text { funcionário que tem interesse se inscreve e a seleção é feita por quem } \\
\text { disponibilizou a vaga. Condição considerada adequada pelos agentes de } \\
\text { saúde, mas adequada e valorosa pelos usuários. }\end{array}$ \\
\hline $\begin{array}{l}\text { Ativos } \\
\text { Estratégicos }\end{array}$ & $\begin{array}{l}\text { Restrições de } \\
\text { mercado devido a } \\
\text { regulamentações. }\end{array}$ & $\begin{array}{l}\text { Serviços prestados sem custo à população. Recurso considerado adequado } \\
\text { e valoroso por todos os respondentes. }\end{array}$ \\
\hline
\end{tabular}

Nota. Fonte: Elaborado pelos autores.

De acordo com os dados obtidos em entrevista ao gestor da Autoridade Sanitária Local (ASL) da UMS Pinheiros ESF a utilização do sistema, mesmo com suas limitações sugere que:

1. Do total de 13.434 habitantes (IBGE, 2010), que fazem parte da área de abrangência, $40 \%$ são SUS dependentes, portanto, esse percentual está dentro da avaliação adequada, uma vez que não atingiu $100 \%$.

2. O número de pessoal é suficiente para atender a população, bem como as atribuições e respectivas tarefas dos funcionários são bem-definidas.

3. Os funcionários recebem treinamento paulatinamente, o que gera satisfação e incentivo à carreira.

4. A estrutura física atende às necessidades da unidade.

5. O total de equipamentos é suficiente.

6. O novo sistema de saúde, cuja implantação é recente, apresenta dificuldades iniciais de implantação, contudo é de fácil utilização e possui importante perspectiva para a sua relação com o SIG e o sistema de distribuição de recursos para futuro próximo.

A partir do desenvolvimento do SIG, para a pesquisa, foi possível perceber que a sede da UMS Pinheiros ESF não se encontra localizada no centro de sua área de abrangência. Isso, possivelmente, deve-se ao fato de ter sido localizada de acordo com a estrutura inicial da região, considerando-se a proximidade com escolas, pontos de ônibus, entre outros fatores. Com o desenvolvimento da região na direção norte, atualmente, a sede não está centralizada. Com o georreferenciamento das gestantes foi possível identificar concentração em algumas áreas, em detrimento de outras. A partir dessa constatação, a unidade de saúde, fazendo uso de um SIG, poderia associar informações socioeconômicas à sua área de atuação e verificar se existe alguma relação, por exemplo, com o poder aquisitivo e a faixa etária e, apoiada em análises espaciais, elaborar planos direcionados de orientação à população (Figura 5). Caso a UMS Pinheiros ESF, bem como as demais Unidades de Saúde incorporassem o SIG, isso passaria a ser um recurso adequado, valoroso e sustentável ao auxiliar nas análises espaciais de necessidades populacionais gerais e específicas e ao contribuir com os demais serviços municipais vinculados à condição de saúde como os de saneamento, transporte e educação.

\section{Conclusões e Recomendações}

O uso de informações, ainda restritas e apontadas por esta pesquisa, por parte da Secretaria de Estado da Saúde sugere, mesmo que parcialmente, benefícios relevantes na distribuição dos recursos. Principalmente, os orientados para os programas oficiais para atendimento da grande população, tais 
como o atendimento à gestante e outros. O uso de informações pela Unidade de Saúde ainda é restrito a uma única informação, como endereço residencial. Os dados sugerem, também, que os recursos e competências analisados nesta pesquisa, voltada à área de saúde pública, mais especificamente, da Unidade Municipal de Saúde Pinheiros/Estratégia de Saúde da Família (UMS Pinheiros ESF), estão dimensionados de modo a atender as necessidades da população de acordo com a análise dos dados obtidos. Entretanto, como contribuição desta pesquisa, o recurso tecnológico Sistema de Informações Geográficas (SIG), não apenas para a UMS Pinheiros ESF como também para as demais Unidades de Saúde de Curitiba e de outros municípios, poderia ser considerado um importante recurso para a avaliação das Unidades de Saúde. Por meio do sistema informacional poderiam ser mapeadas as áreas, microáreas e usuários de todas as unidades, dessa maneira, contribuindo nas análises espaciais de cada unidade, bem como do município de Curitiba, visando auxiliar nas ações de prevenção dos condicionantes que estão diretamente associados às condições de saúde da população como o saneamento, o transporte e a educação e, também relacionados à orientação da população. A utilização da Visão Baseada em Recursos (VBR) associada ao SIG, como elementos de análises, possibilita a identificação dos recursos estratégicos para um adequado atendimento dos propósitos das UMS, sendo imprescindível a identificação das necessidades da população, seu perfil socioeconômico, bem como a sua distribuição espacial.

A VBR tem sido representada pela literatura corrente como uma alternativa que vai além da abordagem da economia industrial, considerando os aspectos internos das organizações. Esta pesquisa, além de sugerir adaptações ao modelo VBR, relaciona-o ao SIG como alternativa de análise em entidades públicas que possuem serviços distribuídos geograficamente, relacionando-os às suas respectivas demandas, nesse caso, dos serviços requeridos pela população do Bairro Jardim Pinheiros (Curitiba/PR). Em condições normais, os serviços públicos dependem de uma aprovação orçamentária única e os recursos são distribuídos igualitariamente. A pesquisa sugere uma maior reflexão nesse sentido ao propor a análise dessa distribuição e considerando os recursos efetivamente necessários em uma determinada localidade. Na revisão de literatura, constatou-se que o único trabalho que associa a VBR e o SIG foi o de Carnasciali e Delazari (2011) para o setor bancário. Já na área de saúde, nenhum trabalho faz essas considerações. É importante destacar que o sistema de saúde é um dos sistemas organizacionais mais complexos no trato de recursos distribuídos. As Unidades Municipais de Saúde de Curitiba, Paraná, atendem as populações que residem em diferentes localidades com características distintas. A sua locação, portanto, é uma decisão estratégica definida para atender a população de maneira preventiva, termo que caracteriza atualmente esse modelo de saúde que adota estratégias de territorialização, agentes comunitários de saúde, programas de saúde da família e educação em saúde e a participação da comunidade. Essas estratégias demandam recursos físicos, humanos, tecnológicos, entre outros, distribuídos ao longo da estrutura, que, ao serem avaliados isoladamente, podem comprometer as análises dos diferentes níveis hierárquicos organizacionais, sejam eles estratégicos, gerenciais e operacionais. Dessa forma, a descrição da definição concomitante de tais recursos e competências traz a contribuição almejada por este estudo.

A atuação dessas unidades de saúde visa buscar alternativas que viabilizem a execução de serviços com custos reduzidos, bem como atender a população na atenção às suas necessidades. Até o final da década de 1980, as políticas de saúde do Brasil não abrangiam toda a população (Dobashi, Brêtas, \& Silva 2011). Andrade (2001) cita que, ao estabelecer a saúde como direito de todos e dever do Estado, o princípio central da reforma sanitária passou a ser garantido pela Constituição Federal, responsável pela regulamentação do Sistema Único de Saúde (SUS).

Segundo Nunes (2007), a Norma Operacional Básica do Sistema Único de Saúde de 01/96 introduziu a competência dos municípios para os serviços de saúde. Essa norma veio aperfeiçoar a gestão desses serviços e a própria organização do sistema, pois reafirma os princípios constitucionais ao definir que o município é o responsável, em primeira instância, pela situação de saúde de sua população, organizando os serviços que estão sob sua gestão e/ou participando na construção do acesso aos demais serviços.

Diante disso, podemos concluir que esta pesquisa inova, uma vez que, além de associar a VBR e o SIG, ela analisa tanto o desenvolvimento dos condicionantes da gestão de recursos e competências 
organizacional, recursos físicos, equipamentos, reputação, inovação, capacidades e ativos estratégicos, como o desenvolvimento do SIG, concomitantemente.

No tocante a recomendações para continuidade desta pesquisa, destaca-se a avaliação dos recursos e competências distribuídos, associando VBR e SIG com expansão para as demais unidades da esfera municipal com abrangência para as demais unidades de saúde ESF, como também para as unidades especializadas pertencentes a esfera de governo estadual e federal. A investigação também pode ser estendida para a investigação especifica de recursos compartilhados, ou ainda, somente recursos tangíveis ou intangíveis. Além do campo da saúde permitir amplos estudos sobre capacidades dinâmicas.

Recomenda-se, também, aprofundar as pesquisas de satisfação da população, que correspondem aos recursos intangíveis, ou seja, são o resultado de conhecimento acumulado e que podem apontar os condicionantes de um atendimento adequado, valoroso e sustentável.

\section{Referências}

Andrade, L. O. M. (2001). SUS passo a passo: gestão e financiamento. São Paulo: Hucitec; Sobral: Uva.

Barney, J. (1992). Integrating organizational behavior and strategy formulation research: a resource based analysis. In P. Shrivastava, A. S. Huff, \& J. E. Dutton (Eds.), Advances in strategic management (Vol. 8, pp. 203-227). Greenwich: Jai Press.

Barney, J. (1994). Commentary: a hierarchy of corporate resources (A. L. Brumagin). In P. Shrivastava, A. S. Huff, \& J. E. Dutton (Eds.), Advances in strategic management (Vol. 10/A, pp. 113-125). Greenwich: Jai Press.

Barney, J. (1996). Gaining and sustaining competitive advantage. Reading, MA: Adisson Wesley.

Barney, J., \& Hesterly, W. (1996). Organizational economics: understanding the relationship between organizations and economic analysis. In S. R. Clegg, C. Hardy, \& W. R. Nord (Eds.), Handbook of organization studies (pp. 115-147). London: Sage Publications.

Bono, J. E., Glomb, T. M., Shen, W., Kim, E., \& Koch, A. J. (2013). Building positive resources of positive events and positive reflection on word stress and health. Academy of Management Journal, 56(6), 1601-1627.

Burrough, P. A., \& McDonnell, R. A. (1998). Principles of geographical information system for land resourse assisssement. Oxford: Claderon Press.

Câmara, G., \& Queiroz, G. R. de (2006). Arquitetura de sistemas de informações geográficas. In G. Câmara, A. M. Monteiro, \& C. Davis (Eds.), Introdução à ciência da geoinformação. Recuperado de http://www.dpi.inpe.br/gilberto/livro/introd/cap3-arquitetura.pdf

Carnasciali, A. M. S. dos, \& Deazari, L. S. (2011). A localização geográfica como recurso organizacional: utilização de sistemas especialistas para subsidiar a tomada de decisão locacional do setor bancário. Revista de Administração Contemporânea, 15(1), 103-125. Recuperado de http://www.scielo.br/pdf/rac/v15n1/v15n1a07.pdf. doi: 10.1590/S1415-65552011000100007

Cobaito, F. C. (2012). Gestão hospitalar, sob a lente da resource based view - RBV. Revista de Administração Hospitalar e Inovação em Saúde, 9, 34-42.

Cowen, D. J. (1988). GIS versus CAD versus DBMS: what are the differences. Photogrammetric Engineering and Remote Sensing, 54, 1551-1554. 
Dobashi, B. F., Brêtas, R., Jr., \& Silva, S. F. (2011). O pacto interfederativo na saúde e a gestão descentralizada: uma oportunidade estratégica de promover avanços no Sistema Único de Saúde? In N. R. Santos \& P. D. C. Amarante (Orgs.), Gestão pública e relação público privado na saúde (pp. 11-23). Rio de Janeiro: Cebes.

Goodchild, M. F. (1992). Geographical information science. International Journal of Geographical Information Systems, 6(1), 35-45. doi: 10.1080/02693799208901893

Grant, R. M. (1991). The resource-based theory of competitive advantage: implications for strategy formulation. California Management Review, 33(3), 114-135.

Instituto Brasileiro de Geografia e Estatística. (2010). Censo 2010. Recuperado de http://www.ibge.gov.br/home/estatistica/populacao/censo2010/tabelas_pdf/total_populacao_par ana.pdf

Instituto de Pesquisa e Planejamento Urbano de Curitiba. (2013, dezembro 16). Mapa base. Recuperado de http://ippuc.org.br/geodownloads/geo.htm

Kay, J. (1996). Fundamentos do sucesso empresarial: como as estratégias de negócios agregam valor. Rio de Janeiro: Campus.

Ministério da Saúde. (n.d.). Sistema de informações geográficas e a gestão da saúde no município. Recuperado de http://www.ripsa.org.br/lildbi/docsonline/get.php?id=006

Noronha, J. C., Santos, I. S., \& Pereira, T. R. (2010). Relações entre o SUS e a saúde suplementar: problemas e alternativas para o futuro do sistema universal. In N. R. Santos \& P. D. C. Amarante (Orgs.), Gestão pública e relação público privado na saúde (pp. 152-179). Rio de Janeiro: Cebes.

Nunes, A. L. (2007). Normas operacionais básicas do SUS. In Associação Paulista de Medicina (Org.), Por dentro do SUS (Vol. 1, pp. 41-42). São Paulo: Editora Atheneu.

Nunes, A. L., \& Queiroz, R. P. (2007). Introdução: o SUS pode ser o melhor plano de saúde. In Associação Paulista de Medicina (Org.), Por dentro do SUS (Vol. 1, pp. 9-12). São Paulo: Editora Atheneu.

Ocké-Reis, C. O. (2011). SUS: o desafio de ser único. In N. R. Santos \& P. D. C. Amarante (Orgs.), Gestão pública e relação público privado na saúde (pp. 101-114). Rio de Janeiro: Cebes.

Oliveira, S. B. de, \& Toda, F. A. (2013). O planejamento estratégico e a visão baseada em recursos (RBV): uma avaliação da tecnologia da informação na gestão hospitalar. Revista Eletrônica de Ciência Administrativa, 12(1), 39-57. Recuperado de http://revistas.facecla.com.br/index.php/recadm/article/download/1247/690. doi: 10.5329/RECADM.2013006

Pina, M. F. R. P. (1998). Potencialidades dos sistemas de informações geográficas na saúde. In A. L. Najar \& E. C. Marques (Orgs.), Os sistemas de informações geográficas: conceitos e aplicações (pp. 125-144). Editora: Fiocruz.

Santos, L. M., Gonçalves, M. A., \& Figueiredo, A. C. (2013, setembro). Avaliação do desempenho da alocação de recursos públicos na atenção básica da saúde: o caso da região sudeste do Brasil. Anais do Encontro Nacional da Associação Nacional de Pós-Graduação e Pesquisa em Administração, Rio de Janeiro, RJ, Brasil, 37. Recuperado de http://www.anpad.org.br/admin/pdf/2013_EnANPAD_APB842.pdf

Secretaria Municipal da Saúde de Curitiba. (2009). Plano municipal de saúde: 2010/2013. Recuperado de http://www.saude.curitiba.pr.gov.br/images/institucional/arquivos/planos/plano_001.pdf 
Stankiewicz, B. (2012). Competitiviness of health resort enterprise: looking for methods of evaluating cross-border competitiviness of health resort enterprise. Economic Review, 41(1), 31-43.

Wernerfelt, B. (1984). A resource-based view of the firm. Strategic Management Journal, 5(2), 171-180.

Xia, J., \& Li, S. (2013). The divestitude of acquired subunits: a resource dependence approach. Strategic Management Journal, 34(2), 131-148. doi: 10.1002/smj.2008 